\title{
The Influence of Social Support on the Prosocial Behavior of College Students: The Mediating Effect based on Interpersonal Trust
}

\author{
Yuan Guo ${ }^{1}$ \\ ${ }^{1}$ School of legal studies, Guangdong University of Foreign Studies, Guangzhou, Guangdong, China \\ Correspondence: Yuan Guo, School of legal studies, Guangdong University of Foreign Studies, Guangzhou, \\ Guangdong, China. Tel: 1-592-049-0789. E-mail: zhaoguohappy@163.com
}

Received: Octoberber 18, 2017 Accepted: November 6, 2017 Online Published: November 9, 2017

doi: 10.5539/elt.v10n12p158 URL: http://doi.org/10.5539/elt.v10n12p158

\begin{abstract}
A sample of 720 college students from 10 different universities at the Guangzhou Higher Education Mega Center are investigated using the Social Support Scale, the Prosocial Behavior Scale, and the Interpersonal Trust Scale. Data are analyzed using SPSS20.0 and Amos7.0. Results show that the subjective support and support utilization of college students directly influences prosocial behavior, and indirectly affects prosocial behavior through the influence of emotional trust and quality trust. Additionally, interpersonal trust plays an intermediary role in the influence of social support on pro-social behavior.
\end{abstract}

Keywords: interpersonal trust, mediating effect, prosocial behavior, social support

\section{Introduction}

In all aspects of morality, responsibility occupies an important position. Prosocial attitudes are one of the most important aspects of many positive mental qualities, as well as an important component of a sound personality and the promotion of individual socialization. The cultivation of prosocial behavior in young students is not only related to the formation of social responsibility and moral behavior, but also to the development, progress, harmony, and stability of a society. Presently, strengthening the cultivation of college students' prosocial behavior has become the focus of educational reform in many parts of the world. Eric Ashby (1974), a famous British scientist on higher education, pointed out that "the essence of the objective of British university education is to make educated people rather than men of learning." Kevin Ryan (1998), director of the Center for the Advancement of Ethics and Character at Boston University, also stressed that "today, the challenge for higher education is to cultivate the moral conscience, morality, civic obligations, and social responsibility of students."

The study of college students' prosocial behavior goes far beyond helping deepen the depth and scope of theoretical research on the subject. The findings of such research can help promote socialization and success in college students. Additionally, it can also provide the theoretical and practical basis for education in morality on colleges and at universities, promoting ideas and methods for the moral education demanded in contemporary social development.

Prosocial behavior refers to the behavior of individuals that consciously make efforts that are beneficial to others in society (Carlo, 2006, 2013; Eisenberg et al., 2006). It is derived from moral cognition, emotions, and value orientations. Prosocial behavior is emphasized by the usefulness of individual behavior and is a direct manifestation of explicit social behavior. However, there are complex psychological phenomena behind it. These include, but are not limited to, moral emotion, personality traits, psychological motivation, value orientation, and cognitive characteristics. Carlo and Brandy (2001) categorized six different behavioral tendencies that present themselves in prosocial acts: the altruistic, urgent, emotional, open, anonymous, and compliant.

Different researchers have discussed the influential factors of prosocial behavior. Virtue Theory holds that prosocial behavior is a spontaneous result of the good character of an individual (Chi, 2005). The Empathy-altruism Hypothesis holds that empathy is the promoting factor in individual prosocial behavior as well as the source behind it (Batson, 1995). Scholarship on the ethics of social norms posits that prosocial behavior depends on an individual's compliance and commitment to the social norms (Yang, 2006). In recent years, studies have found that prosocial behavior is influenced by parenting styles, interpersonal trust, social support, cognitive characteristics, moral emotion, personality traits, as well as social situations. 
Prosocial behavior is an important part of the socialization of college students. Research has shown that the more individual prosocial behaviors one commits, the higher one's subjective well-being, self-efficacy, and self-esteem are (Laihle et al., 2004; Hu et al., 2011), and the better one's positive mood (Yang, 2015) and sense of interpersonal trust are (Rotenberg et al., 2005). In addition, prosocial behavior has been found to be conducive to interpersonal harmony. This imbues individuals with a greater sense of social support from their families and peer groups. This psychological reinforcement helps college students to cope better with the feelings loneliness, anxiety, helplessness, confusion, as well as the other negative emotions that may result from intensive learning as well as interpersonal and social competition (Storch et al., 2003).

There are many factors that influence the prosocial behavior of college students. Interpersonal trust is one of the most important variables. This trust is based on the positive anticipation of the intentions and behaviors of others, the intrinsic motivation of prosocial behavior, as well as the motivation and source of socialization. Trust directly affects the interpersonal communication and subjective well-being of college students. Interpersonal trust encompasses three dimensions: emotional trust, quality trust, and behavior trust. The further study of interpersonal trust can improve scholars' understanding of the mechanisms behind the influencing factors of prosocial behavior.

Social support is an important factor that affects prosocial behavior. This includes both objective support and subjective support. Objective support refers to the interaction of material support and social interpersonal communication. Subjective support is the emotional experience and satisfaction that members of a social circle experience in being respected, supported, and understood in interpersonal communication. Whether subjective or objective support, social support demands individual attention, a sense of externalized support, and the ability to call upon it.

Research has shown that subjective support, objective support, and support utilization have a significant negative predictive effect on college students' apathy and alienation. Social support has a positive role in promoting interpersonal attraction. In line with this, this study confirms that social support for college students is positively related to quality trust, emotional trust, and behavior trust in the overarching categorization of interpersonal trust. In turn, social support also promotes the tendency for prosocial behavior in college students.

Past studies on the subject focus merely on the relationship between social support, interpersonal trust, and the tendencies for prosocial behavior themselves. There is a lack of research that focuses specifically on the mechanisms of their interaction. It has been verified that interpersonal trust plays an intermediary role between social support and altruistic behavior. Building further on these findings, this study assumes that interpersonal trust plays an intermediary role between social support and prosocial behavior. That is, social support directly affects prosocial behavior, but also affects prosocial behavior through interpersonal trust. In addition to the verification of the assumptions detailed above, this paper will also put forward some suggestions for the improvement in the tendencies for prosocial behavior in college students in order to promote the improved cultivation of social responsibility and prosocial behavior in college students.

\section{Research Method}

\subsection{Participants}

In this study, 850 students from 10 universities in the Guangzhou Higher Education Mega Center were selected as the subjects of study. Through the fieldwork, 850 questionnaires were collected with 720 valid questionnaires. The sample rate was approximately $90 \%$. Among the respondents, 415 were male and 305 were female students. The median subject age is 21.1 years old, on a range from 18 to 23.5 years of age.

\subsection{Measuring Tool}

The Social Support Scale was compiled by Xiao. The scale is divided into ten topics covering three dimensions: subjective support, objective support, and support utilization. Since the subjects of this study are college students, some of the problems of the scale were revised accordingly. The categories for "co-worker" and "children" were deleted while the category for "neighbor" was changed to "roommate", "colleague" was changed to "classmate", "husband and wife or spouse" was changed to "lovers", and "work unit" changed to "school". The retest reliability was found to be 0.95 , while the internal consistency coefficient of each dimension of the scale was recorded at $0.89-0.94$. The total a coefficient for this study was 0.89 .

The Prosocial Behavior Scale is a 5-point self-rating Likert scale compiled by the American psychological researcher Carlo Gustavo (2002). The scale was revised and localized by Cong (2008). The scale is divided into six dimensions: public, anonymous, altruistic, compliance, emotional, and emergency behavior. The revised scale has good reliability and validity. The a coefficient for the entire scale is 0.85 , and the total a coefficient for 
the scale in this study was recorded at 0.87 .

The Interpersonal Trust Scale was compiled by Wang (2008). The scale has three dimensions: quality trust, emotional trust, and behavior trust. The scale has good reliability and validity. The scale's total a coefficient is 0.91 , and in this study, the total a coefficient was recorded at 0.88 .

\subsection{Statistical Treatment}

The data processing and analyses for this study were performed using SPSS 20.0 and Amos 7.0.

\section{Analysis of the Results and Discussion}

\subsection{Statistical Description and Correlation Analysis of Social Support, Interpersonal Trust, and Prosocial Behavior}

Table 1. Statistical description and correlation analysis of social support, interpersonal trust, and prosocial behavior $(\mathrm{N}=720)$

\begin{tabular}{lllllllllll}
\hline \multicolumn{1}{c}{ Item } & \multicolumn{1}{c}{$\mathrm{M}(\mathrm{SD})$} & \multicolumn{1}{c}{1} & \multicolumn{1}{c}{2} & 3 & 4 & 5 & 6 & 7 & 8 & 9 \\
\hline 1QT & $28.56(5.66)$ & 1 & & & & & & & & \\
2ET & $20.70(5.14)$ & $0.70^{* *}$ & 1 & & & & & & \\
3BT & $17.12(4.01)$ & $0.46^{* *}$ & $0.56^{* *}$ & 1 & & & & & \\
4IT & $66.23(13.56)$ & $0.66^{* *}$ & $0.63^{* *}$ & $0.59^{* *}$ & 1 & & & & & \\
5PB & $73.32(15.64)$ & $0.50^{* *}$ & $0.40^{* *}$ & $0.22^{* *}$ & $0.52^{* *}$ & 1 & & & & \\
6SS & $20.96(4.52)$ & $0.13^{* *}$ & $0.10^{* *}$ & 0.05 & $0.12^{* *}$ & $0.11^{* *}$ & 1 & & & \\
7OS & $7.57(2.25)$ & 0.03 & $0.12^{* *}$ & 0.01 & 0.05 & 0.03 & $0.25^{* *}$ & 1 & & \\
8DSU & $7.64(1.87)$ & $0.15^{* *}$ & 0.04 & 0.01 & $0.07^{*}$ & $0.11^{* *}$ & $0.16^{* *}$ & $0.14^{* *}$ & 1 & \\
9TSS & $36.25 \pm(6.24)$ & $0.16^{* *}$ & $0.14^{* *}$ & 0.03 & $0.13^{* *}$ & $0.11^{* *}$ & $0.86^{* *}$ & $0.57^{* *}$ & $0.47^{* *}$ & 1 \\
\hline
\end{tabular}

*p $<0.05 ; * * \mathrm{p}<0.01$.

$\mathrm{QT}=$ Quality Trust; ET=Emotional Trust; BT=Behavior Trust; IT=Interpersonal Trust.

$\mathrm{PB}=$ Prosocial Behavior; SS = Subjective Support; OS = Objective Support;

DSU $=$ Degree of Support Utilization; TSS $=$ Total Social Support.

According to the data presented in Table 1, subjective support is positively correlated with the total score for interpersonal trust and prosocial behavior $(\mathrm{r}=0.12, \mathrm{p}<0.01 ; \mathrm{r}=0.11, \mathrm{p}<0.01)$. The degree of support utilization is positively correlated with the total score for interpersonal trust and prosocial behavior $(\mathrm{r}=0.07, \mathrm{p}<$ $0.05 ; \mathrm{r}=0.11, \mathrm{p}<0.01)$. The total score for social support is positively correlated with the total score for interpersonal trust and prosocial behavior $(\mathrm{r}=0.13, \mathrm{p}<0.01 ; \mathrm{r}=0.11, \mathrm{p}<0.01)$.

The results of the study indicate that the more social support a student gets, the higher the interpersonal trust, the more harmonious interpersonal relationship, and the higher the willingness to conduct prosocial behavior. On the contrary, if college students do not have high interpersonal trust, interpersonal relationships are not harmonious, interpersonal indifference develops. Even if a student can receive social support, it will not enhance interpersonal trust, and the student's enthusiasm for prosocial behavior will not be very high. In addition, interpersonal trust is positively correlated with prosocial behavior $(\mathrm{r}=0.50, \mathrm{p}<0.01 ; \mathrm{r}=0.40, \mathrm{p}<0.01 ; \mathrm{r}=0.22, \mathrm{p}<0.01)$. The total score for interpersonal trust is positively correlated with prosocial behavior $(\mathrm{r}=0.52, \mathrm{p}<0.01)$. This indicates that the higher the degree of interpersonal trust, the higher the probability and frequency of prosocial behavior.

\subsection{The Mediating Effect of Interpersonal Trust on the Influence of Social Support and Prosocial Behavior}

First, interpersonal trust plays an important intermediary role in the influence of social support on prosocial behavior. The results provided above show that there is a mutual influence between social support, interpersonal trust, and prosocial behavior. The structural equation model is used to analyze the influence of social support on prosocial behavior and to test the mediating effect of interpersonal trust. Using the Amos program to process the relevant data, the fitting index and a running model of the intermediary function for interpersonal trust are obtained. The results are presented in Table 2. The main reference is as follows: $\mathrm{X}^{2} / \mathrm{DF}<5$. The fitting degree is better. The value range of AGFI, GFI, CFI and NFI is between 0 and 1 . The closer to 1 a value is, the more ideal the model's fitting degree. When the value of RMSEA is less than 0.08 , the fitting degree is better. The 
results show that the fitting degree for the intermediary function of interpersonal trust reaches an ideal level.

Table 2. Main indicators of model fitting for interpersonal trust agency

\begin{tabular}{cccccccc}
\hline $\mathrm{X}^{2}$ & $\mathrm{DF}$ & $\mathrm{X}^{2} / \mathrm{DF}$ & RMSEA & GFI & AGFI & NFI & CFI \\
\hline 82.464 & 32 & 2.577 & 0.067 & 0.958 & 0.920 & 0.921 & 0.949 \\
\hline
\end{tabular}

Table 3. The influence path analysis of the mediation model

\begin{tabular}{lll}
\hline Influence path & Direct impact of standardization & Indirect effect of standardization \\
\hline $\mathrm{SS} \rightarrow \mathrm{IT}$ & $0.214^{*}$ & \\
$\mathrm{IT} \rightarrow \mathrm{PB}$ & $0.619^{* *}$ & \\
$\mathrm{SS} \rightarrow \mathrm{PB}$ & $0.096^{*}$ & $0.133^{*}$ \\
\hline
\end{tabular}

$* \mathrm{p}<0.05 ; * * \mathrm{p}<0.01$.

$\mathrm{SS}=$ Social Support; IT = Interpersonal Trust; PB = Prosocial Behavior.

As shown in Table 3, social support has positive predictive effect on prosocial behavior $(\beta=0.096, p<0.05)$, indicating that the more social support a student gets, the more the student will exhibit prosocial behavior. Interpersonal trust also has positive predictive effect on prosocial behavior $(\beta=0.619, p<0.01)$, indicating that the more harmonious a college student's interpersonal relationships, the more inclined the student is to prosocial behavior. In addition, social support has a positive predictive effect on interpersonal trust $(\beta=0.214, p<0.05)$, indicating that the more social support a student obtains, the higher the student's interpersonal trust. In addition to its direct impact on prosocial behavior, social support indirectly influences college students' prosocial behavior through the intermediary role of interpersonal trust. The ratio between the mediation effect and total effect is $0.133 /(0.096+0.133)=58.08 \%$, which indicates that the social support for college students' prosocial behavior is realized indirectly through interpersonal trust.

Second, improving support utilization and subjective support can promote interpersonal trust. Further analysis is conducted on the impact path of social support, the dimensions of interpersonal trust, and prosocial behavior. The results are presented in Table 4. Among them, subjective support has significant influence on quality trust ( $\beta$ $=0.090, \mathrm{p}<0.05)$ and affective trust $(\beta=0.091, \mathrm{p}<0.05)$. This indicates that when students get attention, recognition, and support from their colleagues, they form better quality trust and interpersonal trust. This increases their trust in their social environment, thereby forming a more harmonious atmosphere of interpersonal trust. Results show that support utilization has a significant effect on quality trust $(\beta=0.142, p<0.01)$. Support utilization is the degree to which an individual may rely or utilize social support. From this analysis, we can deduce that whether college students choose to strengthen their subjective support or invest objective support in their social environment, it is only when they make full use of their social support resources that will they expand their interpersonal trust.

Table 4. Influence path analysis for social support, dimensions of interpersonal trust, and prosocial behavior

\begin{tabular}{llll}
\hline Influence path & Impact of standardization & Indirect effect of standardization & Total \\
\hline $\mathrm{SS} \rightarrow \mathrm{QT}$ & $0.090^{*}$ & & 0.090 \\
$\mathrm{SS} \rightarrow \mathrm{ET}$ & $0.091^{*}$ & & 0.091 \\
$\mathrm{SUD} \rightarrow \mathrm{QT}$ & $0.142^{* *}$ & & 0.142 \\
$\mathrm{QT} \rightarrow \mathrm{PB}$ & $0.397^{* *}$ & & 0.397 \\
$\mathrm{ET} \rightarrow \mathrm{PB}$ & $0.076^{*}$ & & 0.076 \\
$\mathrm{BT} \rightarrow \mathrm{PB}$ & $0.273^{* *}$ & $0.058^{*}$ & 0.273 \\
$\mathrm{SUD} \rightarrow \mathrm{PB}$ & $0.044^{*}$ & $0.054^{*}$ & 0.102 \\
$\mathrm{SUD} \rightarrow \mathrm{PB}$ & $0.053^{*}$ & 0.107 \\
\hline
\end{tabular}

$* \mathrm{p}<0.05 ; * * \mathrm{p}<0.01$.

SS = Subjective Support; QT=Quality Trust; ET=Emotional Trust.

SUD $=$ Support Utilization Degree; $\mathrm{PB}=$ Pro-social Behavior; BT = Behavior Trust. 
Third, the promotion effect of subjective support on quality trust and emotional trust is most obvious variable regarding the prosocial behavior of college students. In the actualization of prosocial behavior, the influence of quality trust is the most pronounced $(\beta=0.397)$, with behavior trust coming in second $(\beta=0.273)$. In addition, through the analysis of the influence paths for prosocial behavior, it is found that subjective support influences the prosocial behavior of college students by increasing quality trust and emotional trust. The indirect effect ( $\beta=$ $0.058)$ is found to be higher than the direct effect $(\beta=0.044)$ in this case. The direct effect $(\beta=0.053)$ and indirect effect ( $\beta=0.054$ ) for support utilization are, on the other hand, basically equivalent.

The analysis provided above shows us that strengthening the subjective support of quality trust and behavior trust has the most significant impact on the prosocial behavior of college students. The more subjective support a college student receives, the more prosocial behavior will be elicited in turn. The key factor here is whether this subjective support increases quality trust and emotional trust in the college student, affecting interpersonal trust more generally. Only when colleges and universities actively advocate honesty and trustworthiness in schoolwork and create a better environment for interpersonal trust can students can feel trusted, respected, supported, and appreciated sufficiently to help to stimulate more prosocial behavior in their ranks.

\section{Summary and Conclusions}

\subsection{Summary}

On a general level, this study has revealed the interaction mechanisms behind social support, interpersonal trust, and prosocial behavior. This study attempts to make up for the lack of research on the relationship between the influencing factors of college students' prosocial behavior. The study's findings have instructive significance for improving the prosocial behavior of college students. Respect, support, peer group acceptance, recognition, and mutual help are found to be the most important sources for subjective support, the critical factor in cultivating prosocial behavior.

First of all, the findings of this study indicate that parents are a critical factor in the development of prosocial behavior in students. Offering genuine respect, trust, recognition and support to adult children is not only conducive to the formation of a healthy parent-child relationship, but additionally fosters mutual love and respect as well as a child's active perception of strong subjective support from the family.

Secondly, the institution of the school is also very important in this respect. School systems must advocate policies that work to increase teachers' positive guidance for students. An example of this is the tutoring program, which provides students with professional learning and career development guidance, but can also guide students' outlook on the world at large as well as their outlook on life and values, and additionally enhance a student's sense of belonging, support, and identity.

Thirdly, society should work more actively to cultivate a culture and atmosphere of caring for the young, specifically students. College students are burdened particularly with pressure and uncertainty regarding their futures. This is especially the case in modern China. Chinese college students gradually step into a high pressure group that foments worry, helplessness, and indecision as a result. Social attention and support imbues them with a fortifying sense of identity, ownership, and trust. Fundamentally, this is derived from their perceived level of social support. Policies must be enacted that work to foster such social support so as to effectively improve the college students' autonomy, relationships, and abilities that reinforce their positive experiences and thereby encourage reinforcing prosocial behavior.

\subsection{Limitations and Future Prospects}

First, although the sample size is large, one must be reminded that all the samples for this study originate from the Guangzhou Higher Education Mega Center. Although a balance of school quality was taken into account for the study's sampling, the limitations inherent in the sampling area limit the extension of the research results to a certain extent. Follow-up studies can consider the selection of more diversified regional and age group samples for validation.

Second, each index variable is dependent upon college students' self-reporting. As such, there may be deviations or inaccuracies present. Combining these tests with behavior observation, parental reporting, school evaluations as well as other methods can help researchers obtain more objective and accurate information on the topic.

Third, although the interaction mechanisms of social support, interpersonal trust, and prosocial behavior has been clarified in this study, long-term research and experimental designs regarding the psychological mechanisms behind prosocial behavior development is still lacking in this study as well as the field more generally. Finally, more should be done to foster prosocial behavior in college students. Schools and teachers can establish more comprehensive and multifaceted systems of evaluation in the moral development and education 
of students that include prosocial behavior specifically. At the same time, based on these evaluations, policy-makers should work to establish comprehensive programs for encouraging and training for such behavior.

\section{Acknowledgments}

This paper is supported by National Education Science of China "the 13th Five-year Plan" 2016 Program (EBA160407): Research on the Formation Mechanism of Prosocial Behaviors of College Students.

\section{References}

Ashby, E. (1974). Adapting universities to a technological society. Jossey-Bass Publishers.

Batson, C. D., Batson, J. G., Todd, R. M., Brummett, B. H., Shaw, L. L., \& Aldeguer, C. M. R. (1995). Empathy and the collective good: caring for one of the others in a social dilemma. Journal of Personality \& Social Psychology, 68(4), 619-631. https://doi.org/10.1037/0022-3514.68.4.619

Carlo, G. (2006). Care-based and Altruistically-based Morality. Handbook of Moral Development (pp. 551-579). London: Psychology Press.

Carlo, G. (2013). The Development and Correlates of Prosocial Moral Behaviors. Handbook of Moral Development (pp. 551-579). London: Psychology Press.

Carlo, G., \& Brandy, A. R. (2001). Are All Prosocial Behaviors Equal? A Social-ecological Development Conception of Prosocial Behavior. Advances in psychology Research, 2.

Chi, Y. K. (2005). The Influence of Personality and Situation Priming on Prosocial Behavior. Doctoral Thesis at East China Normal University.

Carlo, G., \& Randall, B. A. (2002). The Development of a Measure of Prosocial Behaviors for Late Adolescents. Journal of Youth and Adolescence, 31(1), 31-44. https://doi.org/10.1023/A:1014033032440

Cong, W. J. (2008). Research on the Types of Prosocial Behavior of College Students. Master's thesis at Nanjing Normal University, Nov.

Eisenberg, N., Fabes, R. A., \& Spinrad, T. L. (2006). Prosocial Development. Handbook of Child Psychology (Vol. 3): Social, Emotional, and Personality Development. London: Cambridge University Press.

Hu, F. W., \& Ding, H. (2011). The Interaction between Self-esteem and Emotional Information in College Students' Prosocial Behavior Decision-making. New Psychology, June.

Kevin, R. (1998). In Denfence of Character Education. In L. P. Nancci (Ed.) Moral Development and Character Education. Berkeley: McCutchan Publishing Corporation.

Laible, D. J., Carlo, G., \& Scott C. R. (2004). Pathways to Self-esteem in Late Adolescence: The Role of Parent and Peer Attachment, Empathy, and Social Behaviors. Journal of Adolescence, 27(6), 703-716. https://doi.org/10.1016/j.adolescence.2004.05.005

Rotenberg, K. J., Fox, C., Green, S., Ruderman, L., Slater, K., \& Stevens, K. (2005). Construction and Validation of a Children's Interpersonal Trust Belief Scale. British Journal of Developmental Psychology, 23(2), 271-293. https://doi.org/10.1348/026151005X26192

Storch, E. A., \& Masia Warner, C. (2003). The Relationship of Peer Victimization to Social Anxiety and Loneliness in Adolescence Females. Child Study Journal, 33(3), 351-62.

Wang, X. X. (2008). Characteristics of interpersonal trust of college students. Master's thesis at Southwest University, April.

Yang, J. (2006). Research on Prosocial Value Orientation and Prosocial Behavior of College Students. Master's thesis at Huazhong University of Science and Technology.

Yang, Y. (2013). Happiness in the prosocial interaction: the role of autonomy. Advances in Psychological Science, 23(7), 1226-1235. https://doi.org/10.3724/SP.J.1042.2015.01226

\section{Copyrights}

Copyright for this article is retained by the author(s), with first publication rights granted to the journal.

This is an open-access article distributed under the terms and conditions of the Creative Commons Attribution license (http://creativecommons.org/licenses/by/4.0/). 